\title{
Profil Peternak Sapi Perah di Wilayah Desa Kemiri Kecamatan Jabung Kabupaten Malang
}

\author{
Dian Indratmi ${ }^{1}$, Lili Zalizar ${ }^{2}$, Khusnul Khotimah ${ }^{3}$, Anggundari Septiana ${ }^{4}$, Novia Dwi \\ Puspitasari $^{5}$ \\ ${ }^{1}$ Agroteknologi, Fakultas Pertanian Peternakan, Univ. Muhammadiyah Malang -jl. Raya Tlogomas 246 \\ 2,3,4,5 Peternakan, Fakultas Pertanian Peternakan, Univ. Muhammadiyah Malang -jl. Raya Tlogomas 246 \\ E-mail: indratmi_dian@yahoo.co.id, dian@umm.ac.id, HP.085649921614
}

\begin{abstract}
ABSTRAK
Penelitian ini dilakuan di Desa Kemiri Kecamatan Jabung Kabupaten Malang. Penelitian ini bertujuan untuk melihat profil atapun latar belakang dari peternakan di Desa Kemiri dalam peningkatan usaha Peternakan. Responden yang digunakan dalam penelitian ini adalah peternak yang ada didesa Kemiri dengan metode survey. Dari hasil penelitian dapat disimpulkan bahwa usaha peternakan sapi perah masih dapat menarik minat masyarakat, upaya peningkatan kuantitas dan kualitas produksi susu masih perlu dibantu dalam hal sarana dan prasarana, yang diikuti dengan peningkatan pemahaman dan kesadaran untuk memperbaiki manajemen pengelolaan usaha, pemasaran susu yang dilakukan oleh koperasi, masih memerlukan bantuan proteksi dari pemerintah untuk meningkatkan mutu Desa dalam produksi peternakan susu sapi perah.
\end{abstract}

Kata kunci : peternakan; kemiri; jabung; sapi

\section{ABSTRACT}

This research was conducted in Kemiri Village, Jabung District, Malang Regency. This study aims to look at the profile and background of the farm in Kemiri Village in improving the Livestock business. Respondents used in this study were farmers in Kemiri village with survey methods. From the results of the study it can be concluded that the dairy farming business can still attract public interest, efforts to increase the quantity and quality of milk production still need to be assisted in terms of facilities and infrastructure, which is followed by an increase in understanding and awareness to improve business management, milk marketing carried out by cooperative, still need protection assistance from the government to improve the quality of the Village in the production of dairy cattle dairy farms.

Keywords : farms; kemiri; jabung; cattle

\section{PENDAHULUAN}

Usaha peternakan sapi perah di Indonesia saat ini sebagian besar (90\%) masih merupakan usaha peternakan rakyat yang merupakan defenisi usaha tani dalam arti sempit dengan tujuan utama untuk memenuhi kebutuhan subsistensi petani dan keluarganya [1].
Dalam (Sulistyati, Fitriani, \& Hermawan, 2013) biasanya pada suatu daerah yang menjadi sentral susu sapi memiliki pusat pengumpulan yang biasanya disebut dengan Koperasi sebagai wadah pengelola susu hasil peternak yang diharapkan dapat menunjang perekonomian peternak di sekitar wilayah tersebut 
dan menjadikan tempat tersebut sebagai wadah penyaluran [2].

Di desa Kemiri Kecamatan Jabung memiliki kondisi topografi daerah yang cocok untuk iklim peternakan sapi perah dan merupakan sentra peternakan sapi perah. Oleh karena itu untuk pengembangan usaha tersebut, perlu diketahui gambaran atau profil desa dari aspek produksi dan aspek sosial ekonomi peternak sapi perah rakyat yang ada di desa Kemiri, kecamatan Jabung Kabupaten Malang [3].

Secara geografis Desa Kemiri berada pada ketinggian $800-1500 \mathrm{~km}$ dari permukaan air laut. Secara administratif kawasan ini terletak sekitar 26 kilometer dari kota Malang. Desa Kemiri juga merupakan desa penghasil susu sapi terbesar diantara desa yang lain di Kecamatan Jabung. Desa Kemiri adalah desa yang terletak di wilayah Malang Timur, di Kecamatan Jabung. Jarak pusat kota sampai ke desa Kemiri sekitar 26 kilometer, sedangkan ibukota Kecamatan berjarak kurang lebih 6 kilometer.

Secara keseluruhan didapatkan jumlah kepemilikan ternak Sapi/Ekor di daerah Desa Kemiri Kecamatan Jabung adalah 1696/7012 dengan populasi ternak sapi sebesar 6317 di desa Kemiri, hal ini merupakan salah satu tujuan dari penulisan artikel yaitu untuk mengetahui gambaran secara umum peternak sapi perah yang ada di desa Kemiri, Kecamatan Jabung Kabupaten Malang, baik dari aspek produksi, aspek ekonomi, aspek pemeliharaan / perawatan, pemberian pakan, pengolahan serta mekanisme pemasaran hasil ternak.

\section{METODE KEGIATAN}

Metode penelitian ini menggunakan metode survey, yaitu suatu metode penelitian yang dilakukan dengan mengambil sampel dari populasi dan menggunakan kuesioner sebagai alat pengumpul data yang pokok [4]. Data dan informasi yang diharapkan dari warga masyarakat yang diambil sebagai informasi tidak hanya dalam bentuk katakata lisan maupun tulisan, akan tetapi diamati pula tingkah laku dan interaksi sosial mereka dalam kehidupan bermasyarakat. Informasi dikumpulkan dari responden dengan menggunakan daftar pertanyan kerumah peternakan. Penelitian ini menggunakan data primer dan data sekunder, pengumpulan data primer adalah rumah tangga peternak dan peternak yang dikumpulkan ketika penyuluhan. Adapun pengumpulan data sekunder diperoleh dari beberapa instansi terkait Desa, Koperasi dan lembaga lain yang terkait dengan penelitian ini, baik berupa pustaka, hasil penelitian maupun laporan.

\section{KARYA UTAMA}

Desa Kemiri merupakan desa yang terletak di kawasan wilayah Malang bagian Timur, Kecamatan Jabung Jawa Timur. Ibu kota kecamatan jabung berjarak kisaran $6 \mathrm{Km}$ dan Jarak dari pusat kota ke desa kemiri adalah $26 \mathrm{Km}$. Gambaran atau profil Desa Kemiri dapat dijelaskan sebagai berikut: Kondisi geografis ketinggian tempat 1500 meter diatas permukaan laut, suhu rata-rata harian $14^{\circ} \mathrm{C}$, rerata curah hujan 1000 $\mathrm{mm} /$ th. Luas wilayah Desa ladang/tegalan 639,677 degan tingkat kemiringan 0-60 
derajat, lahan kritis sebesar 63 hektar, dengan kondiisi warna tanah hitam kemerahan.

Berdasarkan penelitian ini, peneliti mengambil 34 responden dari peternak, dalam pendidikan, sebagaimana umumnya peternak sapi perah rakyat didominasi dengan tingkat pendidikan SD dan SMP, dengan adanya peternak dengan tingkat pendidikan S1 dan S2 akan menjadi fenomena baru dalam dunia peternakan, sehingga mampu menciptakan peluang bisnis atau perbaikan untuk dunia peternakan di Indonesia ini dan mampu membantu khususnya wilayah kecil yang berpotensi terhadap hasil peternakan untuk meningkatkan hasil peternakan, membangun pola piker maju terhadap masyarakat untuk mampu eksis di dunia peternakan. Dengan adanya KKN-PPM Universitas Muhammadiyah Malang ini diharapkan mampu mewujudkan harapan-harapan penerus generasi dengan adanya calon mahasiswa S1 peternakan dan calon mahasiswa S1 lainnya.

\section{○ Profil pendidikan Responden peternakan sapi perah}

Berdasarkan hasil dari responden dengan 34 sampel yang diberikan, didapatkan latar belakang pendidikan peternakan adalah

Tabel 1: Latar belakang pendidikan peternak desa Kemiri, Kec. Jabung

\begin{tabular}{|c|c|c|}
\hline No & Keterangan & Jumlah \\
\hline 1 & SD & 28 orang \\
\hline 2 & SMP & 3 orang \\
\hline 3 & SMA & 1 orang \\
\hline 4 & $\begin{array}{l}\text { Tidak ada } \\
\text { keterangan }\end{array}$ & 2 orang \\
\hline \multicolumn{2}{|c|}{$\frac{1}{\text { jumlah }}$} & 34 orang \\
\hline
\end{tabular}

Pendidikan merupakan salah satu frame of reference atau kerangka tujuan yang akan mempengaruhi seorang memberi makna pada pesan yang diterimanya [5]. Tingkat pendidikan desa kemiri sebagian besarnya adalah SD. Pendidikan menengah ke atas hanya dapat dihitung beberapa orang saja. Dalam hal ini dapat menjadi kendala untuk memajukan peternakan di Desa Jabung. Menurut (Sulistyati et al., 2013) Latar belakang pendidikan formal responden yang cukup tinggi diikuti dengan tingkat pengetahuan responden merupakan salah satu faktor penunjang bagi responden untuk memahami mengenai pola kemitraan dan cara pemeliharaan. Hal ini berhubungan dengan tujuan diadakannya kegiatan KKN-PPM. Para mahasiswa dituntut untuk membangun pola pikir dan persepsi masyarakat terhadap kemitraan dan cara pemeliharaan dengan cara penyuluhan yang dilakukan oleh peserta KKN-PPM universitas muhammadiyah malang dengan mengandalkan pemahaman dan ilmu yang telah di dapatkan di bangku kuliah dan dibandingkan dengan ilmu yang dipelajari oleh peternak yang masih dengan cara sederhana.

\section{○ Umur Responden}

Umur adalah usia responden yang dihitung sejak lahir sampai penelitian ini dilakukan dalam satu tahun. Hal ini merupakan pengetahuan terhadap peternak tentang tatacara usaha peternakan sapi perah. Klasifikasi umur peternak dapat dilihat dalam tabel berikut: 
Tabel 2. Klasifikasi umur peternak desa

Kemiri berdasarkan responden

\begin{tabular}{|l|l|c|}
\hline No & Umur (tahun) & $\begin{array}{c}\text { Jumlah } \\
\text { Responden }\end{array}$ \\
\hline 1. & Muda (15-25) & 3 \\
2. & Sedang (26-45) & 19 \\
3. & Tua (>45) & 12 \\
\hline \multicolumn{2}{|l|}{ Jumlah } \\
\hline
\end{tabular}

Peternak sapi perah desa kemiri berada pada tingkat usia produktif dengan umur sedang, usia 26-45 adalah 19 orang. Berdasarkan persentase tersebut sebagian besar peternak termasuk ke dalam golongan produktif. Menurut (Prayitno \& Khotimah, 2011) dalam jurnalnya mengatakan bahwa hal ini berhubungan dengan kesiapan fisik (fisik kuat) dan psikologi peternak. Dengan fisik yang kuat mampu memenuhi penyiapan pakan ternak yang diambil dari ladang rumput yang jaraknya relatif jauh. Dengan demikian usia produktif diharapkan untuk mampu meminimalisir resiko dalam usaha sapi ternak. Ketersediaan pakan ternak di dapatkan dari perangkat di desa Kemiri di jelaskan dalam tabel berikut:

Tabel 3. Ketersediaan hijauan pakan ternak

\begin{tabular}{|l|r|}
\hline \multicolumn{1}{|c|}{ Uraian } & \multicolumn{1}{c|}{ Volume } \\
\hline $\begin{array}{l}\text { Luas tanaman pakan ternak } \\
\text { (rumput gajah, dll) (ha) }\end{array}$ & $350 \mathrm{Ha}$ \\
\hline $\begin{array}{l}\text { Produksi hijauan makanan } \\
\text { ternak (Ton) }\end{array}$ & 60ton/Ha \\
\hline Luas lahan gembalaan (ha) & 0 \\
\hline $\begin{array}{l}\text { Dipasok dari luar Kelurahan } \\
\text { (ton) }\end{array}$ & 0 \\
\hline Disubsidi dinas (Ton) & 0 \\
\hline Luas milik perorangan & $21 \mathrm{Ha}$ \\
\hline
\end{tabular}

Sumber: perangkat Desa Kemiri

\section{○ Skala kepemilikan}

Tabel 4. Klasifikasi skala kepemilikan Sapi Perah desa Kemiri

\begin{tabular}{|c|c|l|}
\hline No & \multicolumn{1}{|c|}{$\begin{array}{c}\text { Jumlah Sapi } \\
\text { perah }\end{array}$} & \multicolumn{1}{c|}{$\begin{array}{c}\text { Jumlah } \\
\text { responden }\end{array}$} \\
\hline 1 & Sedikit 1-4 ekor & 14 orang \\
\hline 2 & Sedang 5-8 ekor & 16 orang \\
\hline 3 & Banyak >9 ekor & 4 orang \\
\hline \multicolumn{2}{|c|}{ Jumlah 70 ekor } & 34 orang \\
\hline
\end{tabular}

Tabel 5. Jumlah Sapi yang Produksi

\begin{tabular}{|c|l|l|}
\hline No & \multicolumn{1}{|c|}{$\begin{array}{c}\text { Jumlah sapi } \\
\text { produksi }\end{array}$} & \multicolumn{1}{|c|}{$\begin{array}{c}\text { Jumlah } \\
\text { responden }\end{array}$} \\
\hline 1 & $1-2$ ekor & 13 orang \\
\hline 2 & $3-4$ ekor & 7 orang \\
\hline 3 & $>5$ ekor & 10 orang \\
\hline 4 & Tanpa keterangan & 4 orang \\
\hline Jumlah & 28 ekor & 34 orang \\
\hline
\end{tabular}

Berdasarkan hasil klasifikasi kepemilikan skala sapi perah di desa kemiri di dapatkan jumlah responden terbanyak di kepemilikan sapi di jumlah sedang yaitu 5-8 ekor dengan jumlah keseluruhan sapi perah 70 ekor dari 34 responden, namun tidak semuanya berproduksi, seperti dijelaskan pada tabel jumlah yang produksi hanya didapatkan hasil 28 ekor dengan 4 orang tanpa keterangan, pada skala kepemilikan ini merupakan kepemilikan keluarga belum dikarenakan skala kepemilikan yang masih rendah. Hal ini juga berhubungan dengan cara pemeliharaan yang masih menggunakan cara tradisional dari hasil responden masih banyak yaitu berjumlah 31 orang, modern 1 orang dan di daptkan hasil tanpa keterangan yaitu 2 orang. Menurut [6]. Keberhasilan pengembangan dan keberlanjutan usaha peternakan sapi perah juga ditentukan oleh dimensi infrastruktur maupun teknologi yang 
dikembangkan. Keberhasil dalam usaha sapi perah di desa kemiri bisa dikatakan berkategori sedang karena masih membutuhkan teknologi yang mendukung untuk usaha keberlanjutan peternak sapi.

Tabel 6. Mekanisme pemasaran hasil ternak $75 \%$

\begin{tabular}{|l|l|}
\hline \multicolumn{1}{|c|}{ Uraian } & \multicolumn{1}{c|}{ Pilihan } \\
\hline $\begin{array}{l}\text { Pemasaran Hasil } \\
\text { Ternak }\end{array}$ & Ke Koperasi dan \\
ke tengkulak \\
\hline
\end{tabular}

Sumber: perangkat Desa Kemiri

Jumlah produksi susu setiap hari nya dari peternak dalam responden adalah 731,5 liter/hari jumlah ini merupakan keseluruhan hasil perah peternak dari pagi dan sore hari, hal ini dihitung dari jumlah sapi perah yang produksi. Menurut (Prayitno \& Khotimah, 2011) Hasil pemerahan pada waktu pagi hari lebih banyak daripada sore hari, oleh karena proses metabolisme lebih panjang dan lama serta tingkat stress sapi lebih kecil sehingga dapat memperlancar system metabolisme dalam tubuh sapi . hal ini berkaitan dengan hasik responden yang dilakukan bahwa produksi sapi perah Desa Kemiri pada pagi hari lebih banyak dibandingkan sore hari. Hasil produksi dari peternak baisanya dijual ke KUBE Maju Mapan di Desa kemiri, dan ada beberapa yang menyetorkan hasil produksinya ke pengepul tangki keliling di desa tersebut.

\section{- Hambatan dan harapan peternakan}

Beberapa peternak mengalami pengalaman baik maupun buruk dalam menjalani peternakan. Berdasarkan keterangan peternak hambatan yang dialami peternak yaitu kesulitan pakan, kesehatan hewan ternak, harga produksi susu, perawatan hewan ternak hingga ke perkembangbiakan hewan ternak. Hambatan yang di alami peternakan di Desa Kemiri karena kurangnya pengetahuan dalam hal tersebut, dan penyuluhan dari industry ataupun bidang keilmuan dalam peternakan yang mampu membangun pandangan terhadap peternak sehingga mampu mengembangkan apersepsi peternak untuk peningkatan mutu, harga, dan dalam hal pemeliharaan hewan peternakan.

Dalam usahanya, peternak di desa Kemiri tidak hanya bekerja sebagai peternak, mereka mempunyai usaha sampingan untuk mencukupi kebutuhan keluarga. Beberapa peternak ada juga yang bekerja sampingan sebagai petani kopi karena di desa kemiri juga memiliki perekebunan kopi, hal ini dimanfaatkan peternak untuk memenuhi salah satu kebutuhan hewan ternak juga.

\section{DAMPAK DAN MANFAAT KEGIATAN \\ Kegiatan survei ini bermanfaat bagi} aparat desa selaku pemangku kewenangan pengelola desa, untuk dasar pijakan perumusan kebijakan selanjutnya yang akan diimplementasikan ke masyarakat desa Kemiri. Tentunya kebijakan yang mengarah pada peningkatan kesejahteraan peternak sapi dan kemajuan desa.

\section{KESIMPULAN}

Dari beberapa pembahasan, Desa Kemiri masih masuk dalam Desa yang masih membutuhkan bantuan untuk 
peningkatan mutu Desa sehingga peningkatan peternakan susu sapi perah dapat berajalan sesuai dengan yang di harapkan peternak di Desa Kemiri. usaha peternakan sapi perah masih dapat menarik minat masyarakat, upaya peningkatan kuantitas dan kualitas produksi susu masih perlu dibantu dalam hal sarana dan prasarana, yang diikuti dengan peningkatan pemahaman dan kesadaran untuk memperbaiki manajemen pengelolaan usaha, pemasaran susu yang dilakukan oleh koperasi, masih memerlukan bantuan proteksi dari pemerintah untuk meningkatkan mutu Desa dalam produksi peternakan susu sapi perah

Dalam meningkatkan produksi peternakan susu sapi di Desa Kemiri perlu beberapa upaya baik itu bantuan dari pemerintah, Upaya penyuluhan untuk pengetahuan peternak dan pemerintah dituntut untuk hal tersebut sebagai sarana salah satunya penyejahteraan ekonomi masyarakat

\section{PENGHARGAAN}

Terima kasih disampaikan kepada Kemenristek Dikti atas dukungan dananya melalui hibah pengabdian KKNPPM tahun 2018.

\section{DAFTAR PUSTAKA}

[1] Wahyuningsih, S. (2013). Desa kemiri kecamatan jabung kabupaten
Malang reproductive performance of dairy cattle with varity parity in kemiri village, jabung sub district, malang regency. Jurnal Ternak Tropika, 14(2), 13-22.

[2] Sulistyati, M., Fitriani, A., \& Hermawan. (2013). Global ( potential of small scale dairy farm for facing in global market ). Potensi Usaha Peternakan Sapi Perah Rakyat Dalam Menghadapi Pasar Global (Potential of Small Scale Dairy Farm for Facing in Global Market), 13(1), 17-23

[3] Prayitno, C. B., \& Khotimah, K. (2011). Profil peternak sapi perah desa Kemiri kecamatan Jabung kabupaten Malang. Gamma, 7(September), 13-19. Retrieved from4322/1/profil_peternak_sapi_p erah_di_desa_kemirikecamatan_jab ung_kabupaten_malang.pdf

[4] Singarimbun, Masri dan Sofian Effendi. 1989.Metode penelitian survey. LP3ES. Jakarta

[5] Rachmat, J. 2002. Metode Penelitian Komunikas .Remaja Rosdakarya. Bandung

[6] Sutanto, A., \& Hendraningsih, L. (2011). Analisis keberlanjutan usaha sapi perah di kecamatan ngantang kabupaten Malang. Gamma, 7(1), 1-12. 